Portland State University

PDXScholar

1975

\title{
A Study of the Relationship Between Self-Concept, Public Image, and Consensus Rorschach Performance
}

Dale Sherman Walhood

Portland State University

Follow this and additional works at: https://pdxscholar.library.pdx.edu/open_access_etds

Part of the Psychology Commons

Let us know how access to this document benefits you.

Recommended Citation

Walhood, Dale Sherman, "A Study of the Relationship Between Self-Concept, Public Image, and Consensus Rorschach Performance" (1975). Dissertations and Theses. Paper 2501.

https://doi.org/10.15760/etd.2501

This Thesis is brought to you for free and open access. It has been accepted for inclusion in Dissertations and Theses by an authorized administrator of PDXScholar. Please contact us if we can make this document more accessible: pdxscholar@pdx.edu. 
AN ABSTRACT OF THE THESIS OF Dale Sherman Walhood for the Master of Arts in Psychology presented May 6, 1975.

Title: A Study of the Relationship Between Self-Concept, Public Image and Consensus Rorschach Performance.

APPROVED BY MEMBERS OF THE THESIS COMMITTEE:

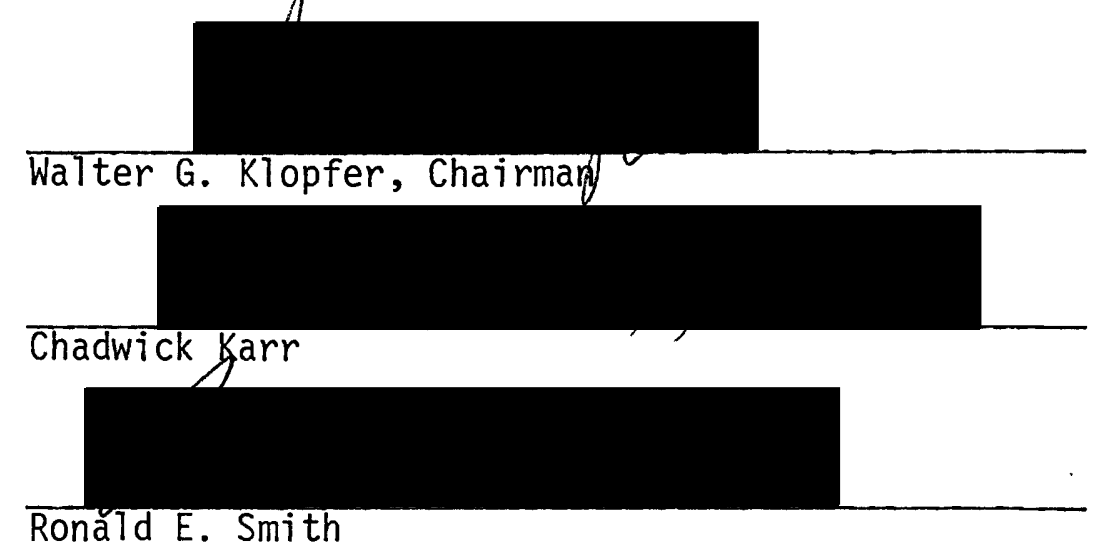

Four measures of dominance were taken on college roommate pairs. Three of the measures were derived from Leary's interpersonal system for diagnosing personality. The fourth measure was derived from the consensus approach to Rorschach administration. Dominance scores for self-concept, public image, predicted image (a new measure in which a person attempts to predict how a significant other sees him) and consensus Rorschach performance were computed. Predicted image correlated higher with self-concept than public image as predicted. Results suggest that dominance as measured by the consensus Rorschach is related to both public image and self-concept. Submissive members appear to understand the structure of the dyad better than their dominant counterparts. Implications for refining the validity of the dominance construct (trait vs. situation) are discussed. 
A STUDY OF THE RELATIONSHIP BETWEEN SELF-CONCEPT, PUBLIC IMAGE AND CONSENSUS RORSCHACH PERFORMANCE

\author{
by
}

DALE SHERMAN WALHOOD

A thesis submitted in partial fulfillment of the requirements for the degree of

MASTER OF ARTS
in
PSYCHOLOGY

Portland State University

1975 
TO THE OFFICE OF GRADUATE STUDIES AND RESEARCH:

The members of the Committee approve the thesis of

Dale Sherman Walhood presented May 6, 1975.
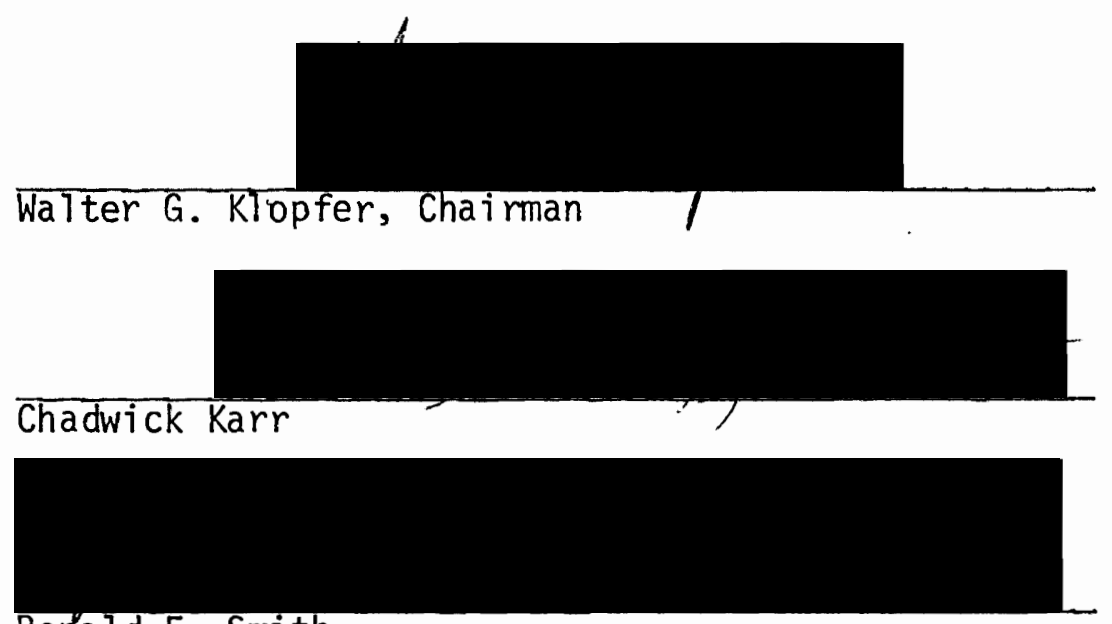

Ronald E. Smith

APPROVED:
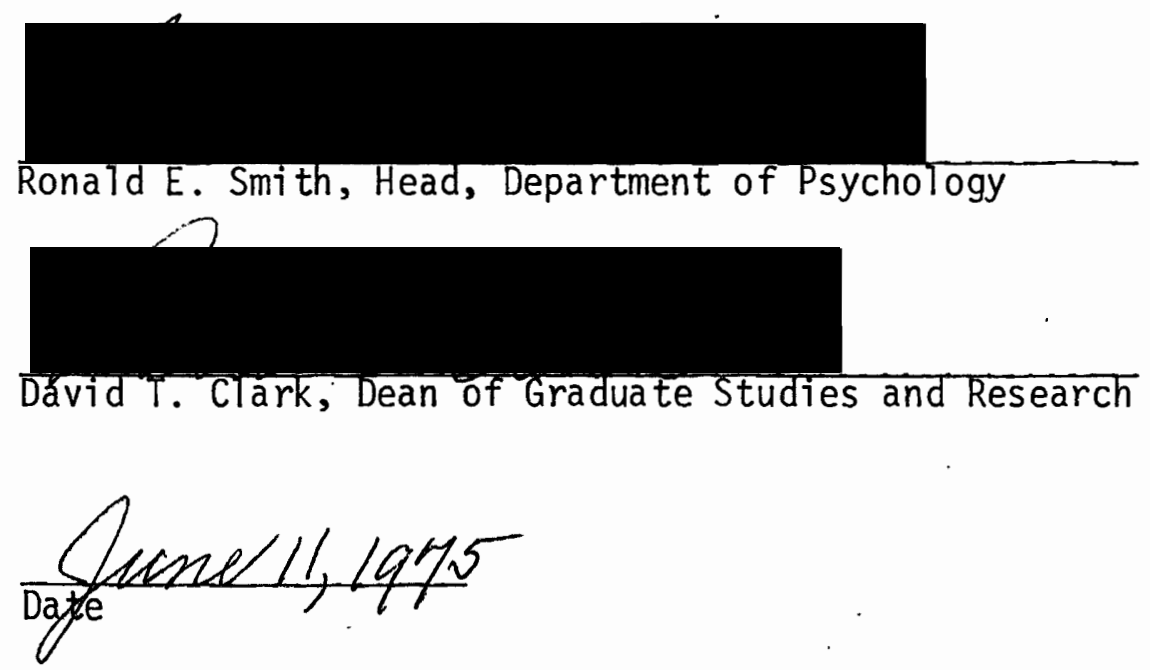
The author would like to acknowledge the faithful advice and counsel rendered over the past five years by Dr. Walter G. Klopfer, Chairman of the thesis committee. His ready accessibility and friendiy manner have been appreciated. The quality of his teaching and his counsel were of immeasurable assistance in the design and selection of the study. His high standards of academic excellence coupled with his keen interest in clinical assessment have hopefully been relfected in this study.

The author gratefully acknowledges the assistance of $\mathrm{Dr}$. Ronald E. Smith...Dr. Smith-has nurtured the author through several psychology courses since the author's undergraduate days and graciously consented to sit for the thesis committee.

A special acknowledgment -is due to Dr. Chadwick Karr who kindly took a seat on the committee that was vacated by the tragic death of Dr.. Horace Manning. Dr. Karr brought a perspective to the study that enabled the author: to refine the test of the main hypothes is and to relate the study to other fields of psychological research.

A word of: thanks is due to Ms. Nancy Junge and to Ms. Betty Wilhelm for the painstaking task of typing this work. Their cheerful. countenance in the face of pressing deadlines was a constant source of encouragement. Acknowledgment is also extended to the Division of Continuing Education, the author's employer, for encouraging the author to pursue the M.A. in psychology.

To the many professors in the Psychology Department who not only gave freely of their time in consultation on academic matters, but also gave freely of themselves when the author experienced a personal tragedy, 
heartfelt appreciation cannot adequately be expressed.

Lastly, but by no means least importantly, the author is indebted to his wife, Patty, who has suffered untold hardship to allow the author to complete this project.

To the many sources quoted in this work, a sincere thanks and much credit for whatever is worthy. The author acknowledges all errors to be his own.

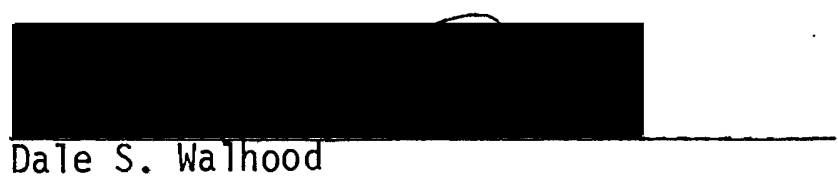


TABLE OF. CONTENTS

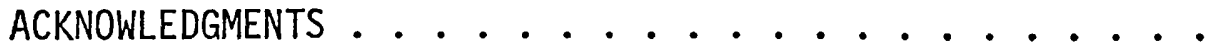

LIST OF TABLES. ...............

INTRODUCTION

Leary's Theory of Interpersonal Diagnosis . . . .

Review of the Literature on Dominance ......

The Consensus Rorschach.

Dominance as a Construct. ..........

Hypotheses to be Tested .........

METHOD.

RESULTS

DISCUSSION.

Applications of the Method.

CONCLUSIONS

REFERENCES . . . . . . . . . . . $i i j$

vi.

1

2

7

11

15

19

22

27

32

39

41

44 


\section{LIST OF TABLES}

TABLE

PAGE

1 Summary of Validation Strategies for Dominance

according to Leary!'s System of Interpersonal

Diagnosis ............

2 All Possible Outcomes of Experiment Where "Self-

knowledge" and "Peer Knowledge" Could

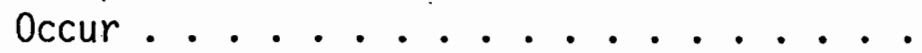

3 Sample Dyad Scores to Indicate Sorting Process

for Trait Versus Situational Analysis...

4 Checklist Correlations of Public Image (Level I),

Predicted Image (Level I-P) and Sëlf-Concept

(Level II). . . . . . . . . .

5 . Comparison of Trait Versus Situational Analysis

for ail Combinations of Four. Propositions.

6 . Frequencies of Propositions Verified and Negated

by Trait Versus Situation, Win Versus Lose

and Self Versus Peer Ratings. ...... 


\section{INTRODUCTION}

Historically psychological assessment has been chiefly concerned with the study of subjects as individuals. Recently, the emphasis has turned from the individual to the relationships that a person is involved in, so that interaction between individuals has become a focus of analysis. The interaction testing movement seems intimately linked to the development of social psychology as a discipline as well as to the re-emergence of the scientist-clinician model in clinical psychology. A recent definition of psychological assessment reflects this change in emphasis. McReynolds (1968, p. 2) states that "By psychological 'assessment' in its most general meaning, we mean the systema'tic use of a variety of special techniques in order better to understand a given individual, group or psychological ecology."

The present thesis is concerned with the relationships among selfconcept, public image, and a new. measure "predicted image" (to be explained later) with consensus Rorschach performance. The consensus Rorschach is a marked departure from the traditional individual administration. In the consensus procedure, two or more people jointly discuss the blots under conditions and instructions established by the examiner. As suggested above, the basic unit to be analyzed is the dyad, the dyad being a two-person group. However, before the research problem can be stated, an understanding is required of the theoretical position taken by Jimothy Leary (1957) with regard to his" interpersonal approach to the diagnosis of personality. 
Leary!'s Theory of Interpersonal Diagnos is

Leary's theory of interpersonal-diagnosis is grounded in the work of Harry Stack Sullivan. Leary \& Coffey (1955) assert that the formulations of Sullivan lend themselves to operational definition leading to objective test. Following Sullivan they make the assumption that "the essence of human happiness and despair, success and failure, centers in the manner in which the person sees, symbolizes, and communicates with others." (Leary \&-Coffey, 1955, p. 75.)

Methodologically this means that to test hypotheses about human emotions and behavioral outcomes, it is necessary to study persons in relation to an interpersonal situation. They distinguish different levels of communication that need to be assessed before an adequate diagnosis of personality can be made. By levels of behavior they mean the perception of behavior coming from different sources of information. The use of levels is congenial to Sullivan!s assertion that two major social forces work on the individual. Both of these forces arise out of the process of social communication. They are: (a) the forces of consensual validation arising from multiple social judgments, and (b) the force of internalized evaluation of those judgments within the individual. Sullivan emphasizes, however, that these two kinds of perceptions (self vs. others) are inextricabiy interwoven and are always involved in the relation of an individual to others.

While self perceptions and information from significant others are often compared and integrated in a clinician's judgments, psychoanalyticallyoriented clinicians have preferred the more symbolic modes of response 
that are expressed in dreams, fantasies and projective tests. Since the prime goal of psychological assessment is personality description, Leary felt that some systematic framework was needed that was operational and could integrate al1 the aforementioned sources of information. What follows is Leary's levels of communication which were devised as a frame of reference that could enable the diagnostician to integrate the evidence gathered from projective tests, self-report and reports from significant others.

As mentioned earlier, levels of behavior refers to the perception of behavior coming from different sources of evidence. Leary isolates five important general levels of communication which are the sources of personality data.

Level I refers to the level of public communication which includes the overt interpersonal behavior of the subject as rated by professional observers or by significant other persons in the client's peer group. Level I measures a person's public image: - Reference hereafter-to .public image" specifically refers to Level I data. Operationally Level I data are gathered by interviewing a subject's peer, spouse, parent, child or anyone that is important in the subject's 1 ife. The interpersonal adjective checklist (ICL) is an instrument that is often used to get an objectively scoreable rating on a subject. This instrument can also be used to get information at other levels.

Level II describes-the level of-conscious description. Level II Y data comes from what the subject reports about interpersonal activity of himself and others, in conversation, in interviews, on questionnaires and on check lists. Level II measures a person's self-concept. However, 
because many psychological theorists include subconscious attitudes in their descriptions of self-concept data, Leary insists that only conscious material be included in this level for purposes of analysis. The present writer's use of self-concept will fortow Leary's definition of -Level II. The third general level of personality data, Level III, Leary calls the level of private symbolization. Data at this level comes from the interpersonal themes expressed in fantasies, dreams and projective tests. This level is very close to what Freud called the preconscious. It includes currently subconscious aspects of a person's personality that are capable of becoming conscious. Level III is usually referred to as the projective or fantasy level since it is tapped by projective assessment tools. Although clinical inferences from projective materials are often used in determining a person's self image, this level is distinct from Level II because the source of inference is based upon operationally different data.

The fourth level-in Leary.'s system is referred-to as the level of the unexpressed unconscious. The source of information here is based upon what seems to be missing. The content of Level IV data is inferred from the significant omissions of common interpersonal themes from all the other levels. Hence, for a given case, it is the last level that can be investigated. Investigation of Level IV is like asking for what is missing from what should be there. For instance, a clinician working with an adolescent might find no reference-in other levels relating to sexua] material. A clinician who concludes that sex is a strong source of anxiety because of its significant omission from other levels would be using a Level IV hypothesis. Operationally, Level IV data can be obtained 
by scoring the ICL for common items that are not checked.

Level $\mathrm{V}$ is termed the level of values or the ego-ideal. Level $\mathrm{V}$ is measured by giving the client an objective personality test with instructions to describe one's "ideal self.". . The clinician also taps this level during the interview by asking the client how he would like to be if he could change himself for the better. The advantage of identifying this level separately can readily be seen when the various levels are compared. Measurable differences between where a person thinks he is and where he wants to be obviously have implications for the science of assessment as well as the art of therapy. A complete discussion of inter-level relationships is beyond the scope of this paper. The above levels represent the structure presented by Leary.

An intermediate level has been proposed by Klopfer. (1968) which is a person's prediction of his public image, termed Level I-P, herein called "predicted image." Level I-P is an intermediate level between Level I (public image) and Level I.I (self-concept). The designation "I-P" is used for consistency with Leary's nomenclature; the- $P$ being an abbreviation for "prediction of public image."

A brief summary of Leary's system of levels, with Klopfer's addition, can be made by viewing each level as a question asked by the clinician as follows:

Lever I How do significant others view the client?

Level I-P How does the client predict that other people see him?

Level II How does the client see himself?

Level III How do preconscious interpersonal themes fit into a description of the client? 
Level IV What common interpersonal themes are unexpressed by virtue of their omission from afl other levels?

Level $V \quad$ How does the client describe his ideal self?

The present study concerns itself with only a small part of a theoretical structure that has the potential of organizing most of the traditiona 1 assessment questions and their resultant data into a cohesive whole. Specifically, I am concerned in this thesis with only the first three questions from the above list of six. The checklist method of assessing variables in human interaction can be used in answering all of the above questions except for Leve] III. Leary's Interpersonal Checklist (ICL) contains sixteen variables that can be summarized by two basic measures, Dom and Lơv. Dom and Lov are assumed to represent the two basic interpersonal needs that people have of each other. 'Dom represents the basic tendancy on the part of persons to be dominant or submissive in their relationships with others. Lov measures the degree of friendliness or hostility evident in interpersonal relationships. The relationship between self-concept and public image for Dom and Lov was the subject of a previous study by Wa Thood and Klopfer (1971). They found that predicted image gives a higher correlation with self-concept than public image for Dom and Lov based upon two independent measures.

The present study focuses on the dominance construct as measured by the ICL and the consensus Rorschach. It was assumed that an investigation relating self-concept and public image to a more direct observational technique such as the consensus Rorschach would not only cast some light on the dominance construct, but would enable a comparison of two different interaction assessment methods that might be linked to the 
trait-state distinction. The predicted-image measure is included as a replication of the previous study. Furthermore, the dominance variable has been exhaustively studied for many years. Measurement strategies that have been used in developing scales for dominance-can-be-found elsewhere (Butt \& Fiske, 1968).

The next section is a review of various previous attempts to validate dominance. Leary's language of levels will be applied to these previous attempts.

\section{Review of the Literature on Dominance}

The review of dominance as validated by several psychological tests will be followed by a review of the consensus Rorschach literature.

Allport \& Allport (1928) were the first under the label of ascendance to study dominance-systematically. Their ascendance-submission reaction study: was validated by ratings. Presumably Level I and Level II data were being correlated.

The Bernreuter Personality Inventory was the next test to include dominance as a scale. As a rationally contrived instrument, the scales were assumed to have face validity (Bernreuter, 1935). Hence, no data are reported regarding the relationship between sources of information that might be related directly to Leary's system. Construct validation data are available, however. The dominance scale of the Bernreuter correlated .72 for males and .66 for females with the dominance scale of the California Psychological Inventory (Gough, 1957, p. 37). These correlations are higher than the CPI's concurrent correlations which were based upon staff and teacher ratings. By inference then, some validity 
for the Bernreuter can be asserted by linking correlations of selfconcept with self-concept which in turn are correlated with public image data.

The Gui] ford-Zimmerman Temperament. Survey:was the next major test to include dominance as a variable. The authors claim factorial validity for the 29 items that make up the scale (Guilford \& Zimmerman, 1949, p. 6). Although "factorial validity" is not included in the technical recommendations of the American Psychological Association (APA, 1954) as a separate category, by inference one can assert that 1) factorial validity cannot be related to a discussion of self-report vs. public image correlations, and 2) factorial validity as determined by these authors is a special case of self-concept vs. self-concept correlation since the basic data entered into a matrix that generates a factorial analysis are correlations of variables within a self-report test. With the exception of ability measures, personality scales which have been constructed on the basis of factorial validity seldom have acceptable levels of either concurrent or predictive validity.

The Thurstone Temperament Schedule was validated for dominance in a straightforward manner. Biserial correlations were computed between ratings of predicted high or low performance on the test and employee's actual, test results. The obtained correlation for this forced-choice procedure was .92 for dominance (Thurston, 1953, p. 10). The number of employees rated by a given employer was not given. Presumably the relationships used by Thurstone in his validation study would meet Leary's criterion of being "significant other."

The longest and one of the most popular tests to have a dominance scale is the California Psychological Inventory. The 48 items in the 
CPI scale were validated by staff ratings of military personnel and teacher's ratings of medical students (Gough, 1957, p. 12). Again in Leary's language we find that the basis for validating dominance is a Level f-Leve\}-II correlation.

The Edwards Personal Preference Schedule includes dominance as a variable. Validation was attempted by having Ss rank themselves on the EPPS variables. The author gives no quantitative results to those rankings (Edwards; 1959, p. 21). As with the Guilford-Zimmerman Temperament Survey, this procedure appears to result in a Level II-Level II correlation. The Cattell Sixteen Personality Factor (16 PF) like the Guilford-Zimmerman Temperament Survey claims factorial va] idity for all its scales. It is argued that correlation to an outside criterion is not meaningful for a multi-purpose test (Catte11, 1962, p. 7). Leary would argue that without an assessment of the various levels that he has outlined, no complete picture of a person is possible. Leary is saying that -unless you also tap an outside-criterion; for example, ratings for significant others, you literaily cannot formulate an adequate persona1ity description.

I am aware that the above review does not do justice to the more. than forty years of research that has been done in the development of dominance scales. The review is intended to demonstrate the Leary's levels of communication reveal the inconsistency with which judgments have been made about the validity of the dominance construct. Table 1 shows a summary by test of the previously cited validation strategies used for dominance according to Leary's system of interpersonal diagnos is . The review is further intended to show that a person's disposition to 
Table 1

Summary of Validation Strategies for Dominance according to Leary's System of Interpersonal Diagnosis

\begin{tabular}{|c|c|c|c|}
\hline \multirow{2}{*}{ Test } & \multicolumn{3}{|c|}{ Corretation Method } \\
\hline & Level I--Leve I II & Level II--Level II & Factorial \\
\hline $\begin{array}{l}\text { Ascendance-submission Reaction } \\
\text { Study (Allport \& Allport) }\end{array}$ & $x$ & & \\
\hline Bernreuter Personality Inventory & & $x$ & \\
\hline $\begin{array}{l}\text { Gui } 1 \text { ford-Zimmerman Temperament } \\
\text { Survey }\end{array}$ & & & $x$ \\
\hline Thurstone Temperament Schedule & $x$ & & \\
\hline California Personality Inventory & $x$ & & \\
\hline $\begin{array}{l}\text { Edwards Personal Preference } \\
\text { Schedule }\end{array}$ & & $x$ & \\
\hline Catte11.16 PF & & & $x$ \\
\hline
\end{tabular}


describe himself as controlling and influential or controlled and submissive has been an important variable in the development of the nonprojective approach to personality assessment. Previous attempts to validate the dominance construct have centered around correlating self-descriptions with ratings from others, or by correlating two self-ratings. Investigators that do not report the above correlations claim "factorial validity" for their dominance scales which is simply an assertion that dominance does not significantly overlap with the other scales on their test. Asserting that correlation to an outside criterion is not meaningfur is definitely not in keeping with contemporary interpersonal psychology.. I believe that previous investigators have chosen the path of least resistance by making the selection of items their central concern. Even though the vast majority of items selected for inclusion in scales of dominance refer directly to interpersonal behavior, sample selection for concurrent validation studies has not included natural groups such as roommate pairs. 'The present study elicited actual interpersonal behavior from paired Ss that is directly compared with both self ratings and peer ratings. After reviewing a variety of available techniques, the consensus Rorschach was chosen as a method for determining the dominance structure of a dyad. Before explaining the design of the present study, we turn to a review of the consensus Rorschach.

The Consensus Rorschach

The consensus Rorschach was selected as a measure of public behavior for a variety of reasons. The stimuli are ambiguous and permit $\underline{S} s$ to give different responses. In the consensus procedure, two or more people 
jointly discuss the blots under conditions and instructions established by the examiner. The task of deciding which of the two responses given by $\underline{S} s$ seems best is an engaging and yet non-threatening task because there are no correct responses. Also-a great deal is known about people's responses to inkblots. Finally, the consensus Rorschach administration enables the $\underline{E}$ to make direct observations of interpersonal behavior in a standardized manner which is objectively scoreable for dominance.

Strodtbeck (1951) is usually credited with first devising a testing procedure whereby $\underline{S} s$ were tested alone-and then together utilizing the same stimuli for both administrations. Strodtbeck used a questionnaire in a cross-cultural study of marital dominance. He called his method the revealed differences technique. The paradigm which found its way into use with the Rorschach is as follows: test subject $A$ alone, test subject $B$ a lone, test subjects $A$ and $B$ together.

The use of the Rorschach in such a manner was first reported by $\mathrm{B} 7$ anchard (1959)-who was interested in determining the group structure of Negro and white groups of delinquent boys who had both participated in gang rape. Blanchard found the group process Rorschach, as he called it, useful in documenting the homesexual impulses of the gang leaders.

Roman \& Bauman (1960) using the Harrower Multiple Choice Rorschach for the individual administration found the consensus approach useful in a variety of clinical problems, including diagnosing schizophrenic motherson interactions and illuminating some of the dynamic aspects of a homosexual relationship. The authors rated agreement responses according to dominance, combination, emergence and reinforcement. They also compared the quality of group responses with the individual responses. 
Loveland, Wynne \& Singer (1963) reported an application of the consensus Rorschach to the study of family interactions. The authors found the consensus method helpfur in diagnosing the disruptive effects of a mother with respect to her-husband and son-- Singer \& Wynne (1965) have compiled a detailed manual for diagnosing schizophrenia from the way patients handle meaning in the consensus situation.

Levy \& Epstein (1964) have also reported using the consensus Rorschach in the family. They perceive the group testing as a method of revealing how the family reaches equilibrium, noting that lack of consensus seems to be predictive of pathology.

Krauser (1964) reported on using the consensus technique in marriage counseling. Emphasizing the dynamic aspects of conjoint protocols, Krauser recommended the approach strongly.

Kimmitt, Reed \& Klopfer (1966) found the consensus approach a promising method of studying the decision-making process as it relates to dominance in children. - The authors concluded that teacher's ratings were the most effective method of determining dominance in the group.

Kaldegg (1966) in an interesting case study of an engaged couple of drug addicts found that the consensus testing seemed to predict a stable mutually reinforcing relationship where other test data did not. The couple was found to be happy in their marriage in an 18-month followup study.

Loveland (1967) has suggested some methodological refinements. He suggests scoring each communication as either imaginative, ordinary, constricted or distorted. The Loveland procedure is to use only one blot but to get a longer sample of behavior from the blot. Loveland also 
recommends that $\underline{E}$ leave the room while $\underline{S}$ sespond to a tape recorder. Cutter \& Farberow $(1968,1972)$ have reviewed the literature with respect to the various scoring systems that have been utilized. Their analysis has centered around the-content polarities that seem-to arise during the consensus administration. The polarities are suggested as being diagnostic of pathology. The authors have also extended the method serially by administering the consensus Rorschach to an alcoholic and alternately to his wife, friends, and roommate.

Thus it can be seen that the consensus use of the Rorschach does not describe one consistent method of tapping interpersonal behavior. Although the previous researchers have all used the Rorschach in groups, what has evolved represents a variety of more or less comparable techniques, with each researcher tending to evolve his own scoring system. As to defining "consensus Rorschach," Farberow (1968) points out that the onty cons istent application of the term is to a protocol elicited by two or more people who are-asked to reach-agreement in their responses to ink-blots. None of-the-researchers-cited related the consensus technique to Leary's system for the interpersonal diagnosis of personality.

An intriguing question that arises out of Leary's system with respect to the consensus Rorschach is at what level of analysis does one treat the consensus Rorschach data. The individual Rorschach is operationally defined as a Level III measure which assesses a person's preconscious interpersonal themes. The person's performance during the consensus administration of the Rorschach, however, appears to be directly observable public behavior. Therefore, the consensus Rorschach data should be more directly comparable with Level I (public image) data than 
Level II (self-concept) data. The present study was designed to investigate this issue.

We have reviewed two general approaches to the study of interpersonal behavior: Leary's interpersonal system and the consensus Rorschach. We have seen that the dominance construct has been investigated using various strategies involving correlations of Leve1 I and Leve1 II data as can be seen in Table 1. Although the consensus Rorschach studies do not address the validation issue, they do suggest a fruitful approach for investigators in the study of behavioral dominance as revealed by the social interaction of pairs of $\underline{S}$. None of the dominance scale validation studies used pairs of $\underline{S}$.

Dominance as a Construct

At this point it is well to review the nature of the hypotheses that have traditionally been tested regarding dominance. From a logical point of view personality tests which attempt to measure dominance have a11. asked individual $\underline{S}$ s to answer true or false to many variable forms of the statement "I am dominant:" The assumption behind normative approaches such as those previously cited is that individual $\underline{S}$ know themselves. Many hypotheses generated by normative studies utilizing individual $\underline{S}$ have somewhere in them the logical (but unproven and untested) assumption that "A knows A." When we look at a dyad the assumption goes from one of "A knows. A" (true or false) to "A knows A" and "A knows B" and "B knows $B$ " and "B knows $A$," anyone of which may be true or false. Only now, with the help of the consensus Rorschach which can divide subject $A$ and subject $B$ into criterion dominant and submissive Ss and with Leary's Levers I and 
II from the ICL for both $A$ and $B$, can we test the assumption of self versus other "knowledge" directly. Throughout this discussion A sha11 refer to the dyad member who is the criterion-dominant member on the basis of having won-a-majority of the consensus -discussions-of the Rorschach ink-blots. Likewise, B shall refer to the consensus Rorschach "loser" or submissive member of the dyad.

The point about self-knowledge needs clarification as it is crucial to the whole thrust of the present argument. The dyad gives us two cases where Level I data can be assessed; namely A's rating of $B$ and B's rating of $A$. The dyad also gives us two cases where Level II data can be assessed; namely $A$ 's rating on himself and $B$ 's rating on himself. In order to completely describe a dyad where dominance is a variable one needs to include a11 four ratings.

If we take the dominant $\underline{S}$ (A's) self-rating for dominance as his prediction of how dominant he feels then we can say that "A knows $A$ " is true if his self-rating and his consensus Rorschach-performance-are-con-sistent. " A knows $A$ " is true if $A$ gives himself a high Dom score on the ICL. In this case "A knows $A$ " is false if he gives himself a low Dom rating on the ICL. The crucial point is that combining consensus Rorschach data and Level I and II ICL data enables one to define operationally a meaning for "self-knowledge." Since an $\underline{S}$ is presumably unaware of his consensus Rorschach behavior, the investigator can determine whether or not an $\underline{S}$ is right or wrong for both his prediction of his own performance, as well as his prediction of his dyad partner's performance. Since there are two members to the dyad and since we have two measures on each member and since each member may be right or wrong regarding his "actual" 
(consensus Rorschach L behayior, there are sixteen possible descriptive outcomes for each dyad in the present experiment. Table 2 shows all sixteen possible outcomes of the experiment outlined above where both "selfknowledge" and "peer knowledge" could occur. In Table 2 the term "peer" refers to dyad partners. As can be seen in Table 2, consensus Rorschach dominance can be related to both Level I and II. In line I we have a case where $A$ (the criterion dominant $\underline{S}$ ) says in effect: "I am dominant and you are submissive." While the criterion submissive member says in effect:- "I am submissive and you are dominant.": In this-case both members of the dyad successfully predict their own as well as the behavior of their partner. Since we know from past experience that objective selfreport measures of dominance such as the ICL do not always agree with other sources of information, we must admit to the possibility that $\underline{S} s$ can be wrong and hence to the sixteen possibilities outlined in Table 2. Note that one can perform the traditional normative analyses by simply combining-al1 Level I ICL data and all Level II ICL data and running a traditional correlation coefficient. With reference to Table 2, one simply combines columns one and three to inspect self-concept data for correlation purposes. To examine public image data one simply pools data from columns two and four. Respecting the integrity of the dyads requires, however, that all sixteen categories be admitted into consideration in an investigation of the relationships among self-concept, public image and consensus Rorschach performance.

One can see from inspecting Table 2 that the question of whether consensus Rorschach performance is closer to self-concept or public image can be creating a false dichotomy since both members can logically predict 
Table 2

A11 Possible Outcomes of Experiment Where "Self-knowledge" and "Peer knowledge" Could.Occur

Level II

Level I

Level II

Level I

\begin{tabular}{|c|c|c|c|c|c|}
\hline & $\begin{array}{l}\text { A knows } A \\
{[\mathrm{WpW}]}\end{array}$ & and & $\begin{array}{c}A \text { knows } B \text { and } \\
{[\mathrm{WpL}]}\end{array}$ & $\begin{array}{l}\text { B knows } B \text { and } \\
{[\text { LpL] }}\end{array}$ & $\begin{array}{c}B \text { knows } A \\
{[\mathrm{LpW}]}\end{array}$ \\
\hline 1. & true & & true & true & true \\
\hline 2. & true & & true & true & false \\
\hline 3. & true & & true & false & true \\
\hline 4. & true & & true & false & false \\
\hline 5. & true & & fal.se & true & true \\
\hline 6. & true & & false & true & false \\
\hline 7. & true & & false & false & true \\
\hline 8. & true & & false & false & false \\
\hline 9. & false.: & & true & true - & true \\
\hline 10. & false & & true & true & false \\
\hline 11. & false & & true & false & true \\
\hline 12. & false & & true & false & false \\
\hline 13. & false & & false & true & true \\
\hline 14. & false & & false & true & false \\
\hline 15. & false & & false & false & true \\
\hline 16. & false & & false & false & false \\
\hline
\end{tabular}


both their own behavior as well as the behavior of their peer as they do in 7 ine 1.

\section{Hypotheses To Be Tested}

The assumptions of the-present-design along with a logical notation used to describe the possible performance of each dyad are as follows:

Each dyad is divided into a dominant member (abbreviated $W$ for winner based upon winning a majority of the consensus discussions of the Rorschach ink-blots) and a submissive member (abbreviated $L$ for the consensus Rorschach discussion loser). Each $S$ will rate both himself (Level II) and his peer (Level I) with the ICL as will be explained in the methods section.

First let us assume that the self-rating of an individual $\underline{s}$ represents his prediction of his own performance on the consensus Rorschach. Let us further assume that the rating given to a peer represents $\underline{S}$.'s prediction of his peer's performance on the consensus Rorschach. This enables us to test the four propositions:

The "winner" predicts his own performance.

The "winner" predicts the 1oser's performance. The "loser" predicts his own performance. The "loser" predicts the winner's performance.

The above four propositions are directly analagous to the four propositions in the four columns defined in Table 2. We can now define in operational terms what is meant by each proposition. "The 'winner' predicts his own performance" means that the winner had a "high" Dom score on his self-rating. This assertion is abbreviated (WpW). "The 'winner' predicts the loser's performance" means that the consensus Rorschach winner rated 
his peer "low" for Dom on the ICL, abbreviated (WpL). Analagously, "The 'loser' predicts his own performance," abbreviated (LPL), means that the loser gave himself a "low" Dom score. And finally, "The 'loser' predicts the-winner's performance"-means that the roser gave the winner a "high" Dom rating, abbreviated (LpW). Note that each proposition can be verified or negated by the-data and that a dyad has not been described unti 1 a)1 four propositions are either verified or negated.

Before proceeding, it is crucial to point out that the determination of a "high" or "low" Dom score can be made in two ways. A Dom score can be -judged "high" or "low"-.in relation to published norms for the ICL, which is the procedure that a "trait" oriented psychologist would use. Or a Dom score can be judged "high" or "low" in relation to the interpersonal situation under investigation, which is the approach that a "situational" psychologist would take. This situational reference can be operationally defined as the dyad median of both $\underline{S}$ self and peer rating scores. Since the data will lend themselves to both analyses, both analyses will be performed. A sample dyad is sorted for-both-trait and situational approaches in the methods section.

The present study is an attempt to relate two general approaches of assessing interpersonal behavior: Leary's interpersonal system, and the consensus Rorschach. Specifically, the study was designed to examine the relationship of two measures of public behavior (Leary's Level I and consensus Rorschach performance) with each other; and with self-concept (Level II). The intermediate measure, a person's prediction of his public image was included as a replication of the studies by Warren \& Klopfer (1965) and Walhood \& Klopfer (1971). The replication hypothesis was that 
predicted image would correlate higher with self-concept than with public image. The replication hypothesis is a normative hypothesis dealing with all the ICL data without regard to dyads or the categories discussed in Table 2.

The main hypothesis, taken from Leary, is the simple assertion that dominance as assessed by the consensus Rorschach would correlate higher with public image than with self-concept. Although a correlation method was to be used originally in the analysis, it was found to be inappropriate after the data was collected because the operational method for fixing dominance for one member of the dyad automatically gives the score for the other member. The sixteen logically possible outcomes outlined in Table 2 also showed that it is possible for both self-concept and public image scores to be consistent with consensus Rorschach performance. However, it was decided to test the hypothesis empirically by sorting the data into the categories represented in Table 2. The hypothesis wout d-be supported if true cases were found more-frequently for. (WpL) and (LpW) than for (WpW) and (LpL).

Upon discovering the relevance of the self-understanding--peerunderstanding model described in Table 2 to a concurrent analysis of dyad outcomes by both trait-nomothetic assumptions versus situational assumptions, an additional hypothesis was formulated. For the trait-situational analysis, it was predicted that fewer categories would be represented under the situational analysis than the trait analysis since ICL scores from Ss who know each other well are more likely to be meaningfully compared with a self-peer median than with a statistical norm. 
METHOD

The Ss were roomate pairs and peer pairs selected from housing provided for students at Portland State University, and from general psychology classes. S pairs were of the same sex. To be included in the sample, $\underline{S} s$ were required to have lived with their peer for a minimum of three months. The minimum length of time that obtained $S$ pairs knew each other was the three months; the maximum seven years; the mode being just under two years.

An attempt was made to balance the composition of pairs so that half were male and half were female. However, due to the relative unwillingness of males to volunteer, the final sample included ten pairs of males and fifteen pairs of females for a total sample of 25 dyads with 50 Ss. To motivate $\underline{S} s$, they were paid two dollars for participating. The experimental session lasted approximately 90 minutes.

The responding pairs were given appointments directing them to present themselves together for testing. The $\underline{S}$ were instructed that the purpose of the study was to examine the relationship between a paper and pencil test and their responses to inkblots. The $\underline{E}$ emphasized that the study was theoretical in nature and that it was the method and not the Ss that interested $\underline{E}$. Feedback was offered by permitting $\underline{S}$ to sign up on a clipboard provided at the end of the experimental session. All but two pairs reques ted feedback.

Upon arriving at the research 1ab, Ss were assigned a code number for their pairs. Letters $A$ and $B$ were part of the code assigned to make sure that checklists and Rorschach data were matched to the appropriate dyad and individual. The $\underline{S}$ receiving an "A" code was immediately brought 
into an adjacent room where he or she was given the checklists with the instructions for "self," "peer," and "predicted image." For the dyadic analysis, the consensus Rorschach dominant member was redesignated " $\mathrm{A}$ " with different color. The wording on the predicted -image ICL was "predict how your roommate (friend) will fill this out on you." The checklist presentation was completely counterbalanced with block randomization of order such that an equal number of Ss received each possible order to control for a possible order effect. While $\underline{S}$ "A" was filling out the ICL'S, $\underline{S}$ "B" was given-the individual Rorschach with an enquiry for location only. The $\underline{S}$ then traded tasks. After both $\underline{S}$ s had taken the individual Rorschach and filled out the ICL's, the Ss were brought together in a small conference room and given the consensus Rorschach with the following instructions:-

You have both given me your responses to these inkblots. Now I would $7 i$ ke you to discuss which of the two responses seems to be the best response for each blot. Please decide on -one response between-the two of you and inform me of your choice.

The $\underline{E}$ then gave $\underline{S}$ the first response that they gave to each blot, alternating giving $A$ 's and $B$ 's response first. If $\underline{S}$ had given identical responses to a blot that response was omitted and their first dissimilar response to that blot was discussed. The "winning" response was recorded by $\underline{E}$ and the $\underline{S}$ who had his response accepted by the losing $\underline{S}$ was given a point for dominance. Thus each $\underline{S}$ received a per cent dominance score for the entire consensus Rorschach administration based upon the number of "winning" responses that $\underline{S}$ obtained.

The checklists were scored for Dom in the usual manner (Leary, 1957, p. 67). Each $\underline{S}$ had a dominance score for consensus Rorschach performance, 
public image, predicted image, and self-concept. Correlations were computed for Level I-Level II, Level I-Level I-P, and for Leve1 II-Level I-P for both Dom and Lov for the total sample and also for males and females. Dyads were divided on the basis of winning and losing a majority of the consensus Rorschach discussions. Dyads were sorted into the categories outlined in Table 2 for both trait and situational analyses as follows. 20 was added to a11 Dom scores to eliminate negatives. As an example of the sorting process, Table 3 shows the Dom scores for dyad number 12, a female $\underline{s}$ pair.

For the trait analysis, the determination of "high" or "low" Dom scores was made by reference to published norms for self-ratings for beginning psychology students at the University of Illinois (LaForge, 1963, p. 35). We first ask if the winner predicted that she would win. The answer is "no" because 18.4 is less than the norm of 20.44 . Hence (WpW) is false. We then see if the winner predicted the behavior of the loser. The answer is "yes" because 9.8 is less than 20.44. Thus (WpL) is true. It should be recalled that the loser's public image (peer rating) comes from the winner. Likewise, the loser predicted that she is submise sive because 16.5 (her Level II) is less than 20.44, meaning that (LpL) is true. Finally, the loser correctly predicts the behavior of the winner because 26.6 is greater than 20.44 indicating that (LpW) is true. So for the four propositions just cited, we find respectively that they are: false, true, true, true. This sequence results in this dyad being sorted into Tine 9 of Table 2.

For the situational analysis, the same process is followed except Level I and II Dom scores are rated "high" or "low" with reference to the median of the dyad scores instead of the published norm. Table 3 shows 


\section{Table 3}

Sample Dyad Scores to Indicate Sorting Process for Trait Versus Situational Analysis

\begin{tabular}{|lc|c|}
\hline & Peer Rating & Self Rating \\
\hline Winner $S_{B}$ & 26.6 & 18.4 \\
Loser $S_{A}$ & 9.8 & 16.5 \\
\hline LaForge norm $=20.44$ (fema le) \\
Dyad median $=17.4$ (midpoint between 16.5 and 18.4) \\
\hline
\end{tabular}


the median for the sample under consideration. For the situational analys is -we can see that the only change is that (WpW) is true since the winner's self-rating is 18.4 which is greater than the dyad median of 17.4. Hence for the situational-analys is the four propositions are-all true-. This sorts our sample dyad into line 1 of Table 2. This procedure was done for 211 dyads and tabulated by males and females and trait versus situational analyses. 


\section{RESULTS}

The replication hypothesis predicted that the new measure, predicted image, would correlate higher with self-concept than public image. Table 4 shows the correlations of self-concept, predicted image, and public image for Dom and Lov scores on the ICL for the total sample and by sex. As hypothesized, predicted image was closer to self-concept than public image. A11 correlations for the replication hypothesis were significant. The main hypothes is was that dominance as assessed by the consensus Rorschach would be more accurately perceived in others [greater frequency of (WpL) and (LpW)] than in oneself [lesser frequency of (WpW) and (LpL)]. Table 5 shows the outcome for each dyad when sorted into the self-prediction, other-prediction categories for both trait and situational methods of analyses. The data in Table 5 is summarized in Table 6 . Table 6 shows in summary form the frequencies at which the propositions were verified and not supported by trait and-situational analyses, by consensus Rorschach winners $(W)$ versus losers $(L)$, and self $[(W p W),(L p L)]$ versus peer $[(W p L)$, $(L p W)]$ ratings. The frequency of confirmed cases was 23 for the trait analysis and 24 for the situational analysis. For self ratings, the frequencies are 23 and 27 respectively. Regardless of analys is, there seems to be no difference between the success of self versus peer ratings, and hence no overall significant relationship between consensus Rorschach performance and Level I or II.

Although no hypothes is was attached to the performance of winners versus losers, it is interesting to note that the consensus Rorschach submissive members success in prediction $[(L \mathrm{LL})$ and $(L p W)]$ is almost twice the frequency as for the consensus Rorschach winner [(WpW) and (WpL)] as 
Table 4

Checklist Correlations of Public Image (Level I),

Predicted Image (Level I-P) and

Self-Concept (Level II)

\begin{tabular}{|c|c|c|c|c|}
\hline \multicolumn{2}{|c|}{ Correlation of Levels } & \multirow[t]{2}{*}{ II-I-P } & \multirow[t]{2}{*}{$I-I-P$} & \multirow[t]{2}{*}{$I-I I$} \\
\hline Trait & Sample & & & \\
\hline Dom & Total & $.80 * *$ & $.52 * *$ & $.44 * \star$ \\
\hline Lov & Total & $.76^{\star \star *}$ & -.09 & .00 \\
\hline Dom & Males & $.88^{\star \star}$ & $.58 * \star$ & $.38 * \star$ \\
\hline Lov & Males & $.73 * *$ & -.18 & -.05 \\
\hline $\operatorname{Dom}^{-} \cdot$. & Femà les $\cdots$ & $.74 * *$ & $.56 * *$ & $.50 * *$ \\
\hline Lov & Females & $.80 * *$ & -.08 & -.05 \\
\hline
\end{tabular}

Total $N=50$

Males $N:=20$

Females $\mathrm{N}=30$

$* * p<0.01$ 
Table 5

Comparison of Trait Versus Situational Analyses for all

Combinations of Four Propositions

\begin{tabular}{|c|c|c|c|c|c|c|c|c|c|c|}
\hline \multirow{3}{*}{ Line } & \multicolumn{4}{|c|}{ Four Propositions } & \multicolumn{3}{|c|}{ Trait Analysis } & \multicolumn{3}{|c|}{ Situational Analysis } \\
\hline & \multicolumn{4}{|c|}{$(W p W)+(W p L)+(L p L)+(L p W)$} & $M$ & $F$ & Total & $M$ & $F$ & Total \\
\hline & $T$ & $T$ & $T$ & $\mathrm{~T}$ & 1 & 1 & 2 & 3 & 2 & 5 \\
\hline 2 & $T$ & $T$ & $T$ & $\mathrm{~F}$ & 0 & 0 & 0 & 0 . & 0 & 0 \\
\hline 3 & $\mathrm{~T}$ & $T$ & $\mathrm{~F}$ & $T$ & 0 & 0 & 0 & 0 & 0 & 0 \\
\hline 4 & $T$ & $T$ & $F$ & $F$ & 0 & 0 & 0 & 0 & 0 & 0 \\
\hline 5 & $\mathrm{~T}$ & $\mathrm{~F}$ & $T$ & $T$ & 1 & 1 & 2 & 0 & 0 & 0 \\
\hline 6 & $T$ & $F$ & $T$ & $F$ & 0 & 1 & 1 & 1 & 4 & 5 \\
\hline 7 & $T$ & $F$ & $\mathrm{~F}$ & $T$ & 1 & 0 & 1 & 0 & 0 & 0 \\
\hline 8 & $T$ & $F$ & $F$ & $F$ & 0 & 1 & 1 & 0 & 0 & 0 \\
\hline-9 & $F \cdot$ & $T$ & $T$ & $T$ & 1 & 2 & 3 & 0 & 0 & 0 \\
\hline 10 & $F$ & $T$ & $T$ & $F$ & 1 & 2 & 3 & 0 & 0 & 0 \\
\hline 11 & $F$ & $T$ & $F$ & $\mathrm{~T}$ & 1 & 1 & 2 & 1 & 2 & 3 \\
\hline 12 & $F$ & $T$ & $F$ & $F$ & 0 & 0 & 0 & 0 & 0 & 0 \\
\hline 13 & $F$ & $\mathrm{~F}$ & $T$ & $T$ & 1 & 1 & 2 & 4 & 3 & 7 \\
\hline 14 & $F$ & $\mathrm{~F}$ & $T$ & $F$ & 1 & 2 & 3 & 0 & 0 & 0 \\
\hline 15 & $\mathrm{~F}$ & $F$ & $F$ & $T$. & 1 & 0 & 1 & 1 & 0 & 1 \\
\hline 16 & $\mathrm{~F}$ & $F$ & $F$ & $F$ & 1 & 3 & 4 & 0 & 4 & 4 \\
\hline Totals & & & & & 10 & 15 & 25 & 10 & 15 & 25 \\
\hline
\end{tabular}


Table 6

Frequencies of Propositions. Verified and Negated by Trait Versus Situation,- Win-Versus - Lose and-Self-Versus. . Peer Ratings

\begin{tabular}{|c|c|c|c|c|}
\hline $\operatorname{Proposition}(\mathrm{s})$ & \multicolumn{2}{|c|}{ Trait } & \multicolumn{2}{|c|}{ Situational } \\
\hline & True .. & False & True & False \\
\hline (WpW) & 7 & 18 & 10 & 15 \\
\hline$(W p L)$ & 10 & 15 & 8 & 17 \\
\hline$(L p L)$ & .16 & 9 . & 17 & 8 \\
\hline$(L p W)$ & 13 & 12 & 16 & 9 \\
\hline$(W p W)+(W p L)$ & 17 & & 18 & \\
\hline$(L p L)+(L p W)$ & $29^{-}$ & & $33^{-}$ & \\
\hline$(W p W)+(L p L) *$ & 23 & & 27 & \\
\hline$(W p L)+(L p W) * *$ & 23 & & 24 & \\
\hline
\end{tabular}

*Self-concept

**Public image 
seen in Table 6.

The prediction that fewer categories would be represented in the situational method than in the trait method appears to be borne out by the observation that in Table 5 only six categories are represented-for the situational analysis while for the trait analysis 12 of the 16 possible categories are represented. 


\section{DISCUSSION}

It is evident from Table 4 that for Dom the new measure, predicted image (I-P), is closer to self-concept than public image as hypothesized. This finding confirms the previous study by Walhood \&Klopfer (1971). An interesting difference from the previous study...is that self-concept and public image are significantly correlated, herein, suggesting that $\underline{S}$ did in fact know each other well. Although no hypothesis was attached to the Lov variable, one would expect that $\underline{\text { Ss }}$ who knew each other well would be able to predict their likeability-by a peer. As previously found and as seen - in Table 4, even the present $\underline{S}$ sere unable to predict their likeability.

The main hypothesis stated that dominance as assessed by the consensus Rorschach would correlate higher with public image than self-concept. For the main hypothesis there was no difference between the success of Levef I versus Level II ratings for either-the-trait or situational analyses:- Al though this : does not lead to a confirmation of consensus Rorschach data as public information data, it seems to suggest that consensus Rorschach dominance is equally related to both levels. If one considers that individual Rorschach data is assigned to Level III where very little awareness of the meaning of the test to the examiner is assumed to be known by the $\underline{S}$, it follows that discussing the blots with a wellknown peer may sensitize Ss differentially to the meaning of the conjoint discussions. Perhaps some Ss "actual" (consensus Rorschach) dominance is well known to them and a cognitive part of their self image, and that for other individuals who have less awareness of their inter-personal behavior, the rating coming from a significant other will be closer to their "actual" performance than their seif image will permit. Simply put, Ss may be more 
or less aware of their social effect on others, and the consensus Rorschach may pick this up. It seems to be the case at least as far as these data are concerned that submissive people as measured by the consensus Rorschach are more aware of the dominance structure of the dyad than their dominant counterparts .

If people indeed are differentialiy aware of their effect on others, this finding suggests that test validators who attempt to validate selfreport scales with ratings from significant others should not expect high correlations. for_all Ss and may need to controt for the fact that "what other people think about me" is differentialiy important to people in general. The clinician who is not so concerned with the psychometric properties of scales may be free to look at the differing sources of information as grist for the diagnostic mill and indeed recognize that the discovery of the congruence or lack of it from self versus other sources of information is part of the properties of dyadic relationships. This may lead to further use of the categories represented-in Tables 2 and 5. The utility of the categories in Table 5 and a discussion of the actual outcomes is worthy of additional clarification.

In line 1, we find a relationship where total agreement exists. Both Ss understand both themseives as well as their peer. One would expect this relationship to be mutually reinforcing. There is not only a dominance structure, but both members understand the structure and behave accordingly. We may have an operational definition of a stable relationship, and possibly also an agreeable or compatible relationship. Two cases (8\%) fit this category for the trait analysis. A trait psychologist who claimed concurrent validity for self-report measures would expect 
more: cases to occur here.

Line 2 describes a relationship where the winner understands himself and his peer and the loser understands himself but not the winner. No cases appear here. It doesn't seem likely that a dominance relationship would occur where the submissive member did not know what the structure was.

Line 3 defines a relationship where again the winner understands both himself. and the loser. The loser, al though predicting the winner, does not predict his own performance. Again, no cases were found for either method of analysis.

It is interesting to compare 1 ines 4 and 14 . Line 4 presents a theoretical relationship where the winner understands both himself and his peer but the loser understands neither himself nor his peer. No cases occurred here. However, the converse of this dyad is 1 ine 13 where the loser understands both parties and the winner understands neither. We find two cases ( $8 \%$ ) for the trait approach and a-striking seven cases (28\%) for the situational analysis. The submissive member is clearly aware of an important aspect of the relationship of which the consensus Rorschach dominant member is unaware. Who then, is primarily responsible for maintaining the relationship? or, is mutual knowledge of the dominance relationship required? Also, is this a compatible relationship?

In line 5 the winner knows himself but not his peer. The loser knows both himself and his peer. The trait analysis again yields two cases $(8 \%)$ while no cases occurred for the situational analysis. This type of relationship would seem to be reasonably stable and possibly mutually agreeable. The onus for adjusting would again fall upon the con- 
sensus Rorschach loser. This would not be too difficult for someone capable of self understanding who also understands the other member of the dyad.

The relationship defined by 1 ine 6 is rather puzzling. Here both winner and loser understand themselves but not their peer. One case occurs for the trait analysis (4\%) while five cases (20\%) occur for the situational analysis. This category is represented by mostly female $\underline{S}$ pairs. Perhaps self-understanding without knowledge of the peer is more important in female dyads than in male dyads. Or perhaps those are dyads of convenience with little or no emotional involvement.

Line 8 defines what one might expect to be a weak relationship. In this case the dominant member predicts her own behavior but no other prediction is verified. One case $(-4 \%)$ occurs for this trait method.

The classification represented by line 9 is the logical converse of line 8 . In this case the winner did not predict his own behavior but the remaining propositions are a 11 -true.-The trait analys is yields three cases-(12\%) while no cases for the situational method.

Line 10 is the converse of line 8 . Here the winner predicts the loser's performance but not his own. The loser predicts his own performance but not the winner's. Again the trait analys is gives three cases (12\%) while nothing emerges on the situational side. The only agreement in this dyad is in regard to who is submissive.

Line 11 describes a dyad where both members predict their peer's behavior but not their own. Two cases (8\%) occur for the trait approach while three cases (12\%) are found under the situational side. One would expect this dyad to be characterized by both members tuning into the 
behavior of their peer.

Line 12 again portrays a theoretical relationship where only the winner predicts the behavior of the loser. No cases were found here.

As previously mentioned, line -1.3 describes another fascinating relationship. The winner predicts nothing correctly but the loser is correct about both himself and the winner. There were no cases found for the logical converse of this case (see line 4). The trait approach has two cases (8\%) while the situational analys is yields seven cases (28\%) for the most frequent category found in the study. In addition, both members of the group think that they are submissive while the consensus Rorschach loser gets the credit for self and peer understanding. We seem to have dramatic evidence that a relationship can be maintained by the "objectively", more submissive member of the pair. Perhaps submissiveness is more important than dominance in making a relationship function. In addition, it would seem likely that the relationship is actually controlled by the submissive member of the dyad..:- Perhaps- "the meek shat. inherit-: the earth:"

Line 14 describes a. dyad where the only true case is that the loser predicts his own performance. Three cases (12\%) occur in the trait investigation. The situational category is empty. This kind of relationship would be characterized by mutual misunderstanding. The winner feels that he or she is also submissive so at least both $\underline{S}$ agree on that. Perhaps the structure of the relationship with respect to dominance is simply not important to members of this type of dyad.

Line 15 defines a similar relationship to the previous one, only in this case the only accurate prediction is the loser's prediction of the 
winner's performance. Both methods of analysis find a single case here ( $4 \%$ of the sample). On the perceptual level these people would describe the structure of the dyad in reverse to its structure as defined by the consensus Rorschach. Perhaps role reversal-is common in this type of infrequent case.

Finally, we come to the last propositional category. Here neither $\underline{S}$ predicts either his own performance nor the performance of his peer. Both trait and situational approaches give four cases (16\%). The writer can suggest that either the dyad members were not aware of the dominance structure or, perhaps these $\underline{S}$ s did not really know each other and participated in the experiment for the money or for some other reason. Or, perhaps this finding indicates the frequency at which the consensus Rorschach does not pick up the "actual" dominance structure of the dyad. It is difficult to conceptualize a relationship where neither member can predict either his own performance or the performance of his peer.

Before turning to a discuss-ion of the results of the trait-versussituation methods of analysis, a systematic finding regarding the ICL means for Dom is essential. Since the sorting of dyads into propositional categories was based upon both self-ratings and peer ratings, a systematic difference between the two might render as artifactual any conclusion based upon them. Three $t$ tests for the difference of means for self concept versus public image were computed. Public image scores were significantly higher than self-concept scores, $t=2.9189, p<0.01$, 98df. For males the difference was still significant, $t=2.509, p<0.05$, $38 \mathrm{df}$. For females the difference between self-concept and public image Dom scores was non-sianificant $(t=0.4735,58 \mathrm{df}$.$) . Because peer ratings$ 
are systematically higher than self-ratings, this might explain why losers get more hits than winners for the analysis demonstrated in Table 5. This is only a problem if one makes broad nomothetic assumptions about the ideal characteristics of dominance as a trait. However, the present research design is neither idiographic nor nomothetic in its assumptions .

This finding may have some relevance to the so-called social desirability issue. Since public image mean ratings are systematically higher than self rating means for Dom, it is possible to assert that $\underline{S}$ are acting to maintain their self-esteem. All Ss are saying in effect "I am submissive" which is socially desirable, and concurrently saying "My peer is more dominant than $I$," which is less socially desirable. Only with $\underline{S}$ pairs and with both self and peer ratings on each other the argument becomes more persuasive regarding the existence of socially desirable traits.

A7though a complete discussion of the trait-situation controversy is beyond the scope of this paper; the present investigator is unaware of any previous-studies that have been designed to investigate the controversy using the same data base to examine both positions.

The present research design incorporates features of both the traitbased approach and the situational approach, but essentially it is neither. Neither the trait approach nor the situational approach is directly concerned with operationally defining self-knowledge. Neither approach has been noted for selecting subject pairs to study interpersonal behavior. Neither approach has a logical propositional form of stating its possible outcomes such that the outcome would have meaning to both theoretical 
positions as well as to the people in the experimental situation. In the present context, the trait-situation controversy seems to be just two different ways of analyzing the same data. If consistency of results is to be a criterion-for evaluating a method of analysis, the situational approach would seem to be more efficient since fewer categories are represented.

Perhaps the present study defines an intermediary approach to the study of personality. This intermediary approach would have the operational definition of self-knowledge as its chief concern. It is concerned with the direct observation of behavior as its primary goal. Relating the direct observation of behavior to self versus "other" sources of information is its secondary goal. But most importantly this design raises self-knowledge to the status of a variable from its shadowy state of assumption.: We are not only attempting to describe an individual, we are attempting to describe an essential dimension of a living interpersonal relationship:--

\section{Applications of the Method}

The present design can fill gaps found in both the trait and situational approaches. For instance, the question of designing an experiment to determine the efficiency of psychotherapy has been a continuing problem in psychology. Again, looking at Table 1, we can assume that the therapeutic process begins with the dyadic relationship defined by category 8 . Substituting the therapist for $A$ and the client for $B$, we have a dyad where the therapist presumably understands himself but the client presumably does not understand himself (or he would not be in need of therapy) 
and the client does not as yet know the therapist. During the assessment phase of the counseling process the therapist gets to know the client, switching the definition of the relationship from line 8 to line 4 . The therapy-process-begins ance the therapist has sufficient understanding of the client to outline a therapy plan which includes increasing the client's awareness of himself and his reiationship. with others, perhaps using the therapist as a model for significant others. Theoretically, the client comes to trust the therapist and to know him, at least in relation to the counseling process. At this point the therapy dyad can be defined as a line 3 relationship. The client may not yet understand himself but he at least has confidence in the therapist ( $B^{-}$knows $A$ ). The therapeutic relationship is complete once the relationship is defined by line 1 . Success of therapy depends upon the patient establishing fine 1 relationships with significant others. Of course, the selection of appropriate assessment techniques as well as the selection of a criterion variable for what cons titutes self-knowledge on behalf of a therapist remains undefined. $\cdots$ The $\cdots$ point is that the logic of the present experiment makes it possible to conceptually organize the therapy process in terms of an operational definition of the relationship with respect to self-understanding. It is also possible to chronicle the progress of therapy through a logical progression of steps to the point where the counseling process can be terminated. 


\section{CONCLUSIONS}

The main conclusion which can be gained from this study is that, as Sullivan stated, self-perception and-perceptions of others are-inextri-cably interwoven. This study has attempted to unravel some of the threads in that tapestry.

While Leary's theory of interpersonal diagnosis of personality seems originally intended for the clinician interested in obtaining a complete description of the individual in his or her psychological ecology, it has been shown to be relevant to an investigation of the validity of the dominance construct. The study was originally intended to be concerned with a comparison of two different approaches to the study of interpersonal behavior. A primary conclusion of the writer is that comparison of the consensus Rorschach-with Leary's levels has implications in several directions. The writer can make no claim to having determined at-which Ievel of analys is the-consensus -Rorschach-should be interpreted. - Rather, consensus Rorschach protocols anaiyzed for dominance seem to be related to both self-concept and public image as a function of an individual's awareness of himself in relation to an interpersonal situation with a suggestion that submissive $\underline{S}$ are more sensitive to the structure of the relationship. Certainly more research is needed on this point. It is also important to note that although assumptions about an individual's self-awareness are needed in programs of personality assessment, these assumptions are magnified exponentially when one tries to do research with

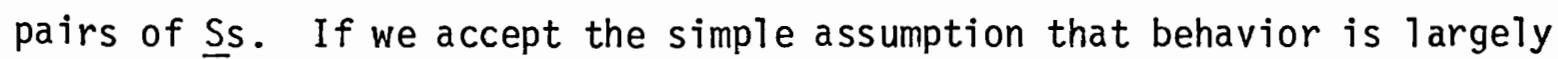
interpersonal, then more studies are needed that utilize natural s pairs. 
While there has been a tendency for contemporary psychology to be divided into a clinical camp preferring the use of projective techniques and an experimental camp concerned with the validation of trait scales, the present study represents a merging of the two schools of thought. More research along this line might well tell us much about the nature of interpersonal behavior.

The new measure, predicted image, has implication for further research. Clearly, the fact that predicted image is closer to self-concept than public image now appears to be a stable finding and suggests that a person's prediction of how he is seen gives a different dimension from either self-image or public image. This prediction seems to be a projection of a person's self image in the direction of how he actually is seen by a significant other person. It is interesting to note that the Edwards Personality Inventory (Edwards, 1970) is based upon the assumption that many personal-adjus.tment problems arise from how people-believe others perceive them.- The present measure goes one step further' by providing accuracy data (predicted image-public image correlation) that could be used in a cross validation of the Edward's test.

The primary value of the present study is logical and analytical rather than empirical. That an integration of the consensus Rorschach with Leary's interpersonal system would lead to an operational definition of self-awareness for dominance was not expected. That this would also lead to an analys is that enables one to concurrently analyze trait versus situational methodology was likewise not anticipated. The basic question as to what level of analys is should consensus Rorschach data be assigned remains unanswered. 
More -research -on the distribution - of naturat dyads - into -the selfprediction, other-prediction categories is certainly needed. The distribution of dyads into categories under the situational approach is intriguing because by implication one would expect to find that in natural dyads: (a) both people know both themselves and their peer, or (b) both people know themselves but not their peer, or $(c)$ both can predict the behavior of their peer but not their own behavior, or (d) the submissive member makes the relationship work, or (e) we have the ever present "noise" effect where the Ss simply do not fit the experimenter's expectations :

That more research is needed cannot be overemphasized. Yet, if research is to be judged by the questions raised as well as answered, then the pursuit of interpersonal constructs using $\underline{S}$ pairs seems like a fruitful enterprise. 


\section{REFERENCES}

Allport, G. W. \& Allport, F. The A-S reaction study: Manual of directions, scoring values and norms. New York: Houghton Mifflin Company, 1928. Reissued 1967.

Bauman, -G. \& Roman, $M$. Interaction product analysis in group and family. diagnosis. Journal of Projective Techniques and Personality Assessment, 1968, 32, 331-337.

Bernreuter, R. G. The personality inventory: Manual. Palo Alto: Stanford University Press, 1935.

Blanchard, W. H. The group process in gang rape. Journal of Social Psychology, 1959, 49, 259-266.

Butt, S. D. \& Fiske, D. W. Comparison of strategies in developing scales for dominance. Psychological Bulletin, 1968, 7.0, 505-519.

Cattell, R. B. Handbook supplement for form C of the sixteen personality factor test. Champaign, INlinois:-. The Institute for Personality and Ability Testing, 1962.

Cutter, F...\& Farberow, N. L. Serial Administration of consensus Rorschach to one patient.. Journal of Projective Techniques and Personality Assessment, $-1968, \overline{32,358-374 .}$

-..-; Consensus Rorschachs in the study of problem behavior. In W. G. Klopfer (Ed.), Developments in the Rorschach Techniques. Vol. 3. New. York: ... Harcourt, Brace \& Wor.1d, 1972:..

Edwards, A. L. Edwards personal preference schedule: Manual. New York: The Psychological Corporation, 1959.

......, Edwards personality inventory: Manual. Chicago: Science Research Associates, 1970.

Farberow, N. L. Symposium: Consensus Rorschachs in the study of problem behavior. Journal of Projective Techniques and Personality Assessment, $1968, \overline{32,326-374 . ~}$

Gough, H. G. Manual for the California psychological inventory. Pato Alto: The Consulting psychologists Press, 1957.

Guil ford, J. P. \& Zimmerman, W. S. The Guilford-Zimmerman temperament survey: Manual of instructions and interpretations. BeverTy Hil 1s: Sheridan Supply Company, 1949.

Kaldegg, A. Interaction testing: An engaged couple of drug addicts tested separetely and together. Journal of Projective Techniques and Personality Assessment, $1966, \overline{30,77-\overline{88}}$. 
Kimmitt, Y., Reed, M. R. \& Klopfer, W. G. The decision-making process as it relates to dominance in children. Journal of School Psychology, $1966,4,37-44$.

Klopfer, W. G. Integration of projective techniques in the clinical case study. In A. I. Rabin (Ed.), Projective techniques in personality assessment. - New łork: Springer Publishing Company, T968; 523-552.

Krauser, E. L. The couples Rorschach: An approach to the understanding of marita] dynamics. Journal of Projective Techniques and Personality Assessment, $1964, \overline{28,55}-63$.

Leary, 7 . Interpersonal diagnosis of personality. New York: The Ronald Press, 1957.

Levy, J. \& Epstein, N. B. An application of the Rorschach in family investigation. Family Process, 1964, 3, (2), 344-376.

Loveland, N., Wynne, L. \& Singer, M. The family Rorschach: A new method for studying family interaction. Family Process, 1963, 2, 187-215.

Loveland, $N$. The relation Rorschach: A technique for studying interaction. Journal of Nervous and Mental Disease, 1967, 145, 93-105.

McReynolds, P., (Ed.), Advances in psychological assessment. Vol. 1. Palo Alto: Science and Behavior, 1968.

Roman, M. \& Bauman, G. Interaction testing: A technique for the psychological evaluation of small groups. . In M. Harrower (Ed.)., Creative variations in the projective techniques.- Springfield, ITlino: : Charles C. Thomas, $1.960, \ldots 93-738 .$.

Singer, M. T. \& Wynne, L. C. Thought disorder and family relations of schizophrenics: III, methodology using projective techniques. Archives of General Psychiatry, 1965, 12, 187-200.

Strodtbeck, F. L. Husband-wife interaction over revealed differences. American Sociological Review, 1951, 16, 468-473.

Thurstone, L. L. Examiner manual for the Thurstone temperament schedule. Chicago: Science Research Associates, 1953.

WaThood, D. S. \& Klopfer, W. G. Congruence between self-concept and public image. Journal of Consulting and Clinical Psychology, 1971, $37,148-150$.

Warren, S. \& Klopfer, W. G. Predicting self-concept in s̀mall groups. 1965, Unpublished study. 